Worldwide research groups are searching for anticancer compounds, many of them are organometalic complexes having platinum group metals as their active centers. Most commonly used cytostatics from this group are cisplatin, carboplatin and oxaliplatin. Cisplatin was used fot the first time in 1978, from this time many platinum derivatives were created. In this review we present biological properties and probable future clinical use of platinum, gold, silver, iridium and ruthenium derivatives. Gold derivative Auranofin has been studied extensively. Action of silver nanoparticles on different cell lines was analysed. Iridium isotopes are commonly used in brachyterapy. Ruthenium compound new anti-tumour metastasis inhibitor (NAMI-A) is used in managing lung cancer metastases. Electroporation of another ruthenium based compound KP1339 was also studied. Most of described complexes have antiproliferative and proapoptotic properties. Further studies need to be made. Nevertheless noble metal based chemotherapheutics and compounds seem to be an interesting direction of research.

Key words: noble metals, platinum, gold, silver.

Contemp Oncol (Pozn) 2015; 19 (4): 271-275 DOI: $10.5114 /$ wo.2015.54386

\section{Noble metals in oncology}

\author{
Anna Markowska ${ }^{1}$, Bartosz Kasprzak², Karolina Jaszczyńska-Nowinka², \\ Jolanta Lubin², Janina Markowska ${ }^{3}$ \\ ${ }^{1}$ Perinatology and Gynecology Department, Poznan University of Medical Sciences, \\ Poznan, Poland \\ 'University Hospital of Lord's Transfiguration, Poznan, Poland \\ ${ }^{3}$ Division of Gynecology, Department of Oncology, Poznan University of Medical \\ Sciences, Poznan, Poland
}

\section{Introduction}

Platinum, ruthenium, rhodium, and iridium (platinum group metals) and gold together with silver (copper group metals) are known as noble metals. They have quite low chemical reactivity compared to other elements.

In this review we discuss the ones that are already used in oncology or have a therapeutic potential.

\section{Platinum}

Platinum (Pt), with atomic number 78, atomic mass 195.08, density 21.45 $\mathrm{g} / \mathrm{cm}^{3}$, and melting point $1772^{\circ} \mathrm{C}$, is quite rare in nature and usually is found together with ruthenium, rhodium, and palladium. In chemical compounds it is mainly found in its oxygenation state of II, III, IV, and VI; it has very good properties of electric and thermal conductivity. Platinum was first found in Columbia in 1735, named from the Spanish "platinum", meaning "small silver" because of its relative lack of usefulness compared to silver, which is called in Spanish "plata". Platinum is mined in Russia, in the Republic of South Africa, Canada, and in the USA. Platinum is used in jewellery, stomatology, and in the motor industry. It is also used broadly in medicine.

Rosenberg et al. [1] used cisplatin firstly for the suppression of Escherichia coli growth. Platinum-based derivatives have found their way to be chemotherapeutics in cancer treatment. The most commonly used cytostatics from this group are cisplatin, carboplatin, and oxaliplatin (used from 1978, 1980, and 1988, respectively). They are used in the therapy of many malignant tumours: ovarian cancer, testicular cancer, lung cancer, oesophageal cancer, stomach cancer, prostate cancer, bladder cancer, squamous cell carcinoma of head and neck, cervical cancer combined with radiotherapy, colorectal cancer and non-Hodgkin lymphoma, multiple myeloma, neuroblastoma, melanoma, and mesothelioma [2].

Cisplatin is built from one atom of platinum, two chloride ions, and two molecules of ammonia. Carboplatin has one atom of platinum, two molecules of ammonia, and a cyclobutanedicarboxyl ligand with oxygen atom from the carboxyl group. Oxaliplatin, however, is a complex compound of platinum with 1,2-diaminocyclohexane and an oxalate group [3]. The addition of new ligands to platinum atom has been done with the aim of breaking chemoresistance to platinum compounds, which is observed during therapy. The search for platinum derivatives is linked to the increase of treatment efficacy. This may be a result of the quantity and type of new DNA adducts and also of the reduction of treatment side effects $[4,5]$.

Cytostatics that are platinum derivatives are alkylating agents. By making stable cross bindings with DNA (bonds with nucleophilic nitrogen atom N7 of two neighbouring guanines) DNA replication is blocked and cell apoptosis is induced. The cell cycle is blocked in the G2 phase. The change of DNA structure is recognised by specific proteins, including the hMSH2 protein form 
the High Mobility Group (HMG), and may cause damage repair; other proteins may be a signal triggering apoptosis [6-9]. Gong et al. [10] found that cisplatin may also induce cell death in parallel by activation of suppressor protein p53 and protein p73. Neoplasms with p53 deficit are resistant to cisplatin treatment. There is, however, evidence that there are other (independent from p53 cell death) pathways in cisplatin based therapies. Cisplatin induces activation of the c-Abl tyrosine kinase, which may induce proapoptotic protein p73 [11-14].

According to the information enclosed with the drug, the most common side effects (more than 1 out of 10 patients) after cisplatin treatment are: leukopenia, thrombocytopenia, anaemia, hypernatremia, impairment of hearing, decreased appetite, nausea, diarrhoea, kidney malfunction, and fever. In more than 1 out of 100 patients but in less than 1 out of 10 patients peripheral neuropathy is observed, especially when cisplatin is combined with taxanes. Side effects of carboplatin include kidney damage (less often than cisplatin), alopecia, fatigue, and elevated liver enzyme activity. Oxaliplatin causes peripheral neuropathy, fatigue, hypernatraemia and hypokalaemia, anaemia, thrombocytopaenia, and leukopaenia.

Platinum derivatives play an important role in oncology. Use of platinum derivatives both in monotherapy and combination therapy can effectively cure cancer.

\section{Gold}

Gold (Au), with atomic number 79, atomic mass 197.0, density $19.3 \mathrm{~g} / \mathrm{cm}^{3}$, and melting point $1063^{\circ} \mathrm{C}$, is found in its free state and in minerals. In chemical compounds it is mainly in oxygenation states I and III; it has very good properties of electric and thermal conductivity.

The history of gold mining is more than 6000 years old, its colour and timeless value were well known in art and architecture of ancient civilisations. The main producer of gold is the Republic of South Africa, although it is also mined in other regions of the world.

Gold was used in medical fields from ancient times. Its complex auranofin is used in rheumatism treatment, and its anticancer potential is also described in both in vitro and in vivo models [15-17].

In recent years nanotechnology using structures of $1 \mathrm{~nm}$ to $150 \mathrm{~nm}$ also involves the use of gold. Nanotechnology is used in immunohistochemistry and gene therapy. Gold particles are stable and non-toxic; they can bind drugs, antibodies, or antigens, they can have transport and active substance release capability. They can also distribute substances to specific body parts or organs. They are safe for healthy tissues because they do not disintegrate during transport $[15,18,19]$.

Numerous studies show that gold complexes have antiproliferative and proapoptotic properties. They reduce tumour mass also in platinum-resistant cancers, and they have lower toxicity, especially for the kidneys [20-22].

The anticancer activity of gold complexes is not known, although some research shows that they may have inhibiting activity towards enzymatic protein complexes like thioredoxin (Trx) and thioredoxin reductase (TrxR); they may also inhibit proteasome activity - a mechanism linked with carcinogenesis [15, 23-27].

Thioredoxin and thioredoxin reductase protect the cell from reactive oxygen species and apoptosis, and they are involved in cell growth and proliferation. Expression of thioredoxin is increased in many malignant carcinomas - it is one of the factors that is linked to cell chemoresistance; it is also linked to cells' invasive and metastatic potential. Thioredoxin also causes expression of hypoxia-induced factor 1 (HIF-1 $\alpha$ ) and increases production of protein products from the VEGF gene promoting neoangiogenesis in tumours $[15,28,29]$.

Thioredoxin and thioredoxin reductase are found in two forms: cytoplasmic and mitochondrial (TrxR1 and TrxR2).

Gold complexes inhibit thioredoxin reductase in $\mathrm{mi}$ tochondria by reducing membrane potential, leading to apoptosis [15, 21]. It is thought that the enzymatic complex of thioredoxin - thioredoxin reductase can be a target in cancer therapy $[26,28]$.

Another anticancer mechanism of gold is inhibition of the proteasome complex. This is a complex responsible for degradation of ubiquitin marked proteins that may cause selective apoptosis of cancer cells [16, 20].

Gold complexes are also responsible for telomerase and STAT pathway inhibition. STAT pathway is a transcription activator that plays a role in proliferation and has an antiapoptotic effect on cancer cells [30].

Recent research has shown evidence anticancer activity of gold complexes both in vitro and in vivo. It was proven that auranofin in human ovarian cancer cell lines induces apoptosis by inhibition of thioredoxin reductase; it was also proven on cisplatin-resistant cell lines [21]. A similar action of gold (III) complex was observed on human ovarian cancer stem lines, and in one study it was compared with cisplatin and oxaliplatin. Antiproliferative and proapoptotic actions of gold complexes were stronger than those of platinum derivatives [22]. In another study gold complexes were assessed for their antiproliferative potential in ovarian cancer cell lines and embryonic cell lines - it was found that they selectively inhibit thioredoxin reductase in cancer cells [24].

A study on human breast cancer showed that the use of auranofin also has an anticancer effect; the inhibition mechanism was linked to the STAT pathway and telomerase [30]. It was found that the effectiveness of pegylated gold nanoparticles (AUNPS) combined with docetaxel on prostate cancer cell lines was $50 \%$ - only half of cells survived, others were damaged [31]. An even higher effectiveness of gold nanoparticles was observed in xenograft of human prostate cancer in mice with the use of particles having gold $\mathrm{Au}^{198}$ isotope [32].

Gold nanoparticle complex was developed, and this complex was linked to the cetuximab antibody and gemcitabine, which was administered to animals that had hepatocellular carcinoma (HCC) heterografts. Heterografts entered apoptotic pathway, they were found to be necrotic, their proliferative potential was diminished, and healthy tissues were not damaged [33].

An interesting study on auranofin use in transgenic mice with chronic lymphocytic leukaemia (CLL) was made. This type of leukaemia has a high remission rate after 
first-line chemotherapy, although relapses are linked to chemoresistance. Auranofin has been seen to reduce tumour size, extending overall survival [34].

It seems that gold complexes and nanoparticles, because of their anticancer activity, will find their way into clinical trials, not only experimental models.

\section{Silver}

Silver (Ag, lat. argentum), with atomic number 47, atomic mass 107.86 , density $10490 \mathrm{~kg} / \mathrm{m}^{3}$, and melting point $961.78^{\circ} \mathrm{C}$, is found in nature in its free state and in minerals like argentite. It is a silver-white metal, with very good thermal and electrical conductivity. Silver was mined for the first time in $2500 \mathrm{BC}$ in Asia Minor.

Silver was known for its antibacterial properties in ancient times. Greeks coated plates and cups with silver to stop disease spreading, and they put silver coins into water buckets to extend the water's freshness. They also gave silver spoons to children for sucking, which was believed to protect them from illnesses. The very first silver compound that was used for treatment was silver nitrate, which was discovered by Basilius Valentinus back in the $15^{\text {th }}$ century [35].

In the $19^{\text {th }}$ century, for the first time, $0.2 \%$ solution of silver nitrate was used for burn wound care. In 1874 T. Billroth proved the antiseptic properties of silver by using its antibacterial effect on Staphylococcus aureus. Later on the antibacterial properties of silver were proven against the following bacteria: Streptococcus, Pseudomonas and Escherichia [36]. In the early 1990s it was observed that people with low concentrations of silver as a trace element often undergo bacterial, viral, or fungal infections [37]. Nowadays many surgical instruments are silver coated, as well as other instruments like dialysis catheters. Everywhere where risk of infection is present, silver can be used.

In the last few years oncological research was dominated by nanoparticles, some of which included silver. The first report of the cytotoxic effect of silver nanoparticles (AgNPs) was proven against MCF-7 breast cancer cell line in 2013 [38]. Researchers developed silver nanoparticle synthesis with the use of plant extracts. Kathiravan [39] used the extract of Melia dubia leaves (a tree growing in India), and Sathishkumar [40] used extract from Dendrophthoe falcata. Silver nanoparticles developed in this way were proven to have an anticarcinogenic effect on MCF-7 breast cancer cell line. Vasanth [41], with the use of AgNPs, stopped replication of a cervical cancer cell line (HeLA) by induction of apoptosis. To produce silver nanoparticles he used extract from the bark of Moringa oleifera. Chinese researchers have proven the cytotoxic effect of silver nanoparticles against AML (acute myeloid leukaemia) cell lines such as SHI-1, THP-1, DAMI. This effect was greater against those cells than against normal hematopoietic cells [42]. Yu-Len Li [43] investigated three mononuclear complexes with quinoline. He proved that those complexes inhibit proliferation by inducing cell cycle cessation in phase G1 and S in hepatocellular carcinoma cell line (HepG2). Lacatelii [44] investigated the glioblastoma cell line (U87MG). He observed in vivo tumour reduc- tion when a silver nanoparticle was combined with alisertib (selective kinase inhibitor).

Therapy with silver nanoparticles is an alternative to conventional chemotherapy. Current research on those nanoparticles looks very promising, but further investigation is needed.

\section{Iridium}

Iridium (Ir), with atomic number 77 , atomic mass 192.217 , density $22.56 \mathrm{~g} / \mathrm{cm}^{3}$, and melting point $2466^{\circ} \mathrm{C}$, is found in nature as osmiridium (an alloy of osmium and iridium). In chemical compounds it is mainly in an oxygenation state of IV; oxygenation states II, III, and VI are also possible, and it has good properties of electric and thermal conductivity.

Discovered in 1803 by Smithson Tennant, iridium belongs to the platinum group. Iridium was named after the greek rainbow goddess Iris because of its different coloured salts. It is one of the most dense and least reactive elements in nature. Annual production of iridium is only 3 tonnes; it is one of the rarest elements in nature. At easily creates complex compounds.

Until now, in areas linked to medicine, iridium has been used together with platinum as a component of electrodes for stimulation [45]. Iridium oxide was used instead of Ag/ $\mathrm{AgCl}$ in dry electrodes with microtips that could be used without gel EEG [46]. Because of the high price of iridium there was an attempt to produce electrodes with titanium-iridium oxide [47].

In oncology iridium has found its way as $1 r^{192}$ isotope in brachytherapy. Its half-life is only 74 days. Iridium sources are small and thin. They can be used in after-loading systems that protect medical staff from radiation. It is one of the basic isotopes used in brachytherapy. In the field of gynaecological oncology it is used mainly in plesiobrachytheraphy in cervical and uterine cancer $[48,49]$.

Research was made on the use of iridium in Flt4 (also known as VEGFR3) kinase inhibitor [50, 51].

\section{Ruthenium}

Ruthenium (Ru), with atomic number 44, atomic mass 101.07, density $12.45 \mathrm{~g} / \mathrm{cm}^{3}$, and melting point $2334^{\circ} \mathrm{C}$, is found in nature as sulphide, iron, and chrome ores. In chemical compounds it is mainly in oxygenation state IV. Oxygenation states II, III, VI, and VIII are also possible. Annual mining of ruthenium is only 20 tonnes. Some researchers claim that ruthenium was first discovered in 1808 by Jędrzej Śniadecki; he called this element vestium in honour of the discovery of the planet Vesta [52].

The first ruthenium compound used in clinical practice was NAMI-A. It was proven to be effective in managing lung cancer metastases. Currently NAMI-A is used together with gemcitabine as second-line chemotherapy in the treatment of metastases in non-small cell lung carcinoma [53].

Other compounds used in clinical practice are KP1019, and soluble salt KP1339, which has finished phase I of a clinical trial in neuroendocrine carcinomas [54]. Electroporation of KP1339 was tested in Slovenia, and this meth- 
od was found to be effective in vivo because of its extra antiangiogenic properties. It may also spread the idea of electrochemotherapy, which is based on local injection of chemotherapeutics accompanied by electrical impulses [55].

Ruthenium was also used in photodynamic therapy $[56,57]$. Nanocompounds based on ruthenium derivatives have been developed. Mangiapia et al. developed DoHuRu, HoThyRu, and ToThyRu, which are AziRu derivatives, and together with phospholipids they created stable nanoaggregates. The antiproliferative activity of nanocompounds towards cell lines WiDr, C6, and MCF-7 was also studied [58].

The authors declare no conflict of interest.

\section{References}

1. Rosenberg B, van Camp L, Krigas T. Inhibition of cell division in Escherichia coli by electrolysis products from a platinum electrode. Nature 1965; 205: 698-99.

2. http://chemocare.com/chemotherapy/drug-info/cisplatin.aspx.

3. Timerbaev AR, Hartinger CG, Aleksenko SS, Keppler BK. Interactions of antitumor metallodrugs with serum proteins: advances in characterization using modern analytical methodology. Chem Rev 2006; 106: 2224-48.

4. Kozelka J, Legendre F, Reeder F, Chottard JC. Kinetic aspects of interactions between DNA and platinum complexes. Coord Chem Rev 1999; 190-192: 61-81.

5. Chaney SG, Campbell SL, Bassett E, Wu Y. Recognition and processing of cisplatin- and oxaliplatin-DNA adducts. Crit Rev Oncol Hematol 2005; 53: 3-11.

6. Pizarro AM, Sadler PJ. Unusual Dna binding modes for metal anticancer complexes. Biochemie 2009; 91: 1198-211.

7. Gelasco A, Lippard SJ. NMR solution structure of a DNA dodecamer duplex containing a cis-diammineplatinum(II) $d(G p G)$ intrastrand cross-link, the major adduct of the anticancer drug cisplatin. Biochemistry 1998; 37: 9230-9.

8. Barbec $\mathrm{V}$, Kasparkowa J. Molecular aspects of resistance to antitumor platinum drugs. Drug Resist Updates 2002; 5: 147-61.

9. Jordan P, Carmo-Fonseca M. Molecular mechanisms involved in cisplatin cytotoxicity. Cell Mol Life Sci 2000; 57: 1229-35.

10. Gong JG, Costanzo A, Yang HQ, Melino G, Kaelin WG Jr, Levrero M, Wang JY. The tyrosine kinase c-Abl regulates p73 in apoptotic response to cisplatin-induced DNA damage. Nature 1999; 399: 806-9.

11. Anthoney DA, Mcllwrath AJ, Gallagher WM, Edlin AR, Brown R. Microsatellite instability, apoptosisand loss of p53 function in drug-resistant tumour cells. Cancer Res 1996; 56: 1374-81.

12. Gallagher WM, Cairney M, Schott B, Roninson IB, Brown R. Identification of $p 53$ genetic suppressor elements which confer resistance to cisplatin. Oncogene 1997; 14: 185-193.

13. Zamble DB, Jacks T, Lippard SJ. p53-dependent and -independent responses to cisplatin in mouse testicular teratocarcinoma cells. Proc Natl Acad Sci U S A 1998; 95: 6163-8.

14. Jost CA, Marin MC, Kaelin WG Jr. p73 is a human p53-related protein that can induce apoptosis. Nature 1999; 389: 191-4.

15. Śliwińska-Hill U, Celmer J, Trynda-Lemiesz L. Związki złota jako potencjalne leki przeciwnowotworowe nowej generacji. Nowotwory 2013; 63: 456-62.

16. Nagy EM, Ronconi L, Nardon C, Fregona D. Noble metal-dithiocarbamates precious allies in the fight against cancer. Mini Rev Med Chem 2012; 12: 1216-29.

17. Liu C, Liu Z, Li M, Li X, Wong YS, Ngai SM, Zheng W, Zhang Y, Chen T. Enhancement of auranofin-induced apoptosis in MCF-7 human breast cells by selenocystine, a synergisticinhibitor of thioredoxin reductase. PLoS One 2013; 8: e53945.
18. Dreaden EC, El-Sayed MA. Detecting and destroying cancer cells in more than one way with noble metals and different confinementproperties on the nanoscale. Acc Chem Res 2012; 45: 1854-65.

19. Ahn S, Lee IH, Kang S, Kim D, Choi M, Saw PE, Shin EC, Jon S. Gold nanoparticles displaying tumor-associated self-antigens as a potential vaccine for cancer immunotherapy. Adv Healthc Mater 2014; 3: 1194-9.

20. Casini A, Messori L. Molecular mechanisms and proposed targets for selected anticancer gold compounds. Curr Top Med Chem 2011; 11: 2647-60.

21. Marzano C, Gandin V, Folda A, Scutari G, Bindoli A, Rigobello MP. Inhibition of thioredoxin reductase by auranofin induces apoptosis in cisplatin-resistant human ovarian cancer cells. Free Radic Biol Med 2007; 42: 872-81.

22. Coronnello M, Mini E, Caciagli B, Cinellu MA, Bindoli A, Gabbiani C, Messori L. Mechanisms of cytotoxicity of selected organogold (III) compounds. J Med Chem 2005; 48: 6761-5.

23. Arnér ES, Holmgren A. The thioredoxin system in cancer. Semin Cancer Biol 2006; 16: 420-6.

24. Schuh E, Pflüger C, Citta A, Folda A, Rigobello MP, Bindoli A, Casini A, Mohr F. Gold(I) carbene complexes causing thioredoxin 1 and thioredoxin 2 oxidation as potential anticancer agents. J Med Chem 2012; 55: 5518-28.

25. Karlenius TC, Tonissen KF. Thioredoxin and cancer: A role for Thioredoxin in all states of tumor oxygenation. Cancers (Basel) 2010; 2: 209-32.

26. Szokalska A. Układ tioredoksyna-reduktaza tioredoksyny jako nowy cel terapii przeciwnowotworowych. Post Biol Kom 2008; 35: 391-402.

27. Ronconi L, Fregona D. The Midas touch in cancer chemotherapy: from platinum - to gold-dithiocarbamato. Dalton Trans 2009; 28: 10670-80.

28. Biaglow JE, Miller RA. The thioredoxin reductase/thioredoxin system: novel redox targets for cancer therapy. Cancer Biol Ther 2005; 4: 6-13.

29. Welsh SJ, Bellamy WT, Briehl MM, Powis G. The redox protein thioredoxin-1 (Trx-1) increases hypoxia-inducible factor 1alpha protein expression: Trx-1 overexpression results in increased vascular endothelial growth factor production and enhanced tumor angiogenesis. Cancer Res 2002; 62: 5089-95.

30. Kim NH, Park HJ, Oh MK, Kim IS. Antiproliferative effect of gold(I) compound auranofin through inhibition of STAT3 and telomerase activity in MDA-MB 231 human breast cancer cells. BMB Rep 2013; 46: 59-64.

31. de Oliveira R, Zhao P, Li N, de Santa Maria LC, Vergnaud J, Ruiz J, Astruc D, Barratt G. Synthesis and in vitro studies of gold nanoparticles loaded with docetaxel. Int J Pharm 2013; 454: 703-11.

32. Shukla R, Chanda N, Zambre A, et al. Laminin receptor specific therapeutic gold nanoparticles (198AuNP-EGCg) show efficacy in treating prostate cancer. Proc Natl Acad Sci U S A 2012; 109 : 12426-31.

33. Raoof M, Corr SI, Zhu C, Cisneros BT, Kaluarachchi WD, Phounsavath S, Wilson LJ, Curley SA. Gold nanoparticles and radiofrequency in experimental models for hepatocellular carcinoma. Nanomedicine 2014; 10: 1121-30.

34. Fiskus W, Saba N, Shen M, et al. Auranofin induces lethal oxidative and endoplasmic reticulum stress and exerts potent preclinical activity against chronic lymphocytic leukemia. Cancer Res 2014; 74: 2520-32.

35. Klasen HJ. Historical review of the use of silver in the treatment of burns. I. Early uses. Burns 2000; 26: 117-30.

36. Klasen HJ. Historical review of the use of silver in the treatment of burns. Renewed interest for silver. Burns 2000; 26: 130-8.

37. Silver S. Bacterial silver resistance: molecular biology and uses and misuses of silver compounds. FEMS Microbiol Rev 2003; 27: 341-53.

38. Jeyaraj M, Sathishkumar G, Sivanandhan G, et al. Biogenic silver nanoparticles for cancer treatment: an experimental report. Colloids Surf B Biointerfaces 2013; 106: 86-92.

39. Kathiravan V, Ravi S, Ashokkumar S. Synthesis of silver nanoparticles from Melia dubia leaf extract and their in vitro anticancer activity. Spectrochim Acta A Mol Biomol Spectrosc 2014; 130: 116-21. 
40. Sathishkumar G, Gobinath C, Wilson A, Sivaramakrishnan S. Dendrophthoe falcata (L.f) Ettingsh (Neem mistletoe): a potent bioresource to fabricate silver nanoparticlesfor anticancer effect against human breast cancer cells (MCF-7). Spectrochim Acta A Mol Biomol Spectrosc 2014; 128: 285-90.

41. Vasanth K, Ilango K, MohanKumar R, Agrawal A, Dubey GP. Anticancer activity of Moringa oleifera mediated silver nanoparticles on human cervical carcinoma cells byapoptosis induction. Colloids Surf B Biointerfaces 2014; 117: 354-9.

42. Guo D, Zhu L, Huang Z, et al. Anti-leukemia activity of PVP-coated silver nanoparticles via generation of reactive oxygen species andrelease of silver ions. Biomaterials 2013; 34: 7884-94.

43. Yu-Lan L, Qi-Pin Q, Yun-Feng A, et al. Study on potential antitumor mechanism of quinoline-based silver (I) complexes: Synthesis, structural characterization, cytotoxicity, cell cycle and caspase-initiated apoptosis. Inorganic Chemistry Communications 2014; 40: 73-7.

44. Locatelli E, Naddaka M, Uboldi C, et al. Targeted delivery of silver nanoparticles and alisertib: in vitro and in vivo synergistic effect against glioblastoma. Nanomedicine (Lond) 2014; 9: 839-49.

45. Ganske G, Slavcheva E, van Ooyen A, Mokwa W, Schnakenberg U. Sputtered platinum-iridium layers as electrode material for functional electrostimulation. Thin Solid Films 2011; 519: 3965-70

46. Dias NS, Carmo JP, da Silva FA, Mendes PM, Correia JH. New dry electrodes based on iridium oxide (IrO) for non-invasive biopotential recordings and stimulation. Sensors an Actuators A: Physical 2010; 164: 28-34.

47. Cruz AM, Casan-Pastor N. Graded conducting titanium-iridium oxide coatings for bioelectrodes in neural systems. Thin Solid Films 2013; 534: 316-24.

48. Pötter R, Knocke TH, Fellner C, Baldass M, Reinthaller A, Kucera H. Definitive radiotherapy based on HDR brachytherapy with iridium 192 in uterine cervix carcinoma: report on theVienna University Hospital findings (1993-1997) compared to the preceding period in the context of ICRU 38 recommendations. Cancer Radiother 200; 4: 159-72.

49. Gupta AK, Vicini FA, Frazier AJ, Barth-Jones DC, Edmundson GK, Mele E, Gustafson GS, Martinez AA. Iridium-192 transperineal interstitial brachytherapy for locally advanced or recurrent gynecological malignancies. Int J Radiat Oncol Biol Phys 1999; 43 . 1055-60.

50. Leung $\mathrm{CH}$, Zhong HJ, Shiu-Hin Chan D, Ma DL. Bioactive iridium and rhodium complexes as therapeutic agents. Coordin Chem Rev 2013; 257: 1764-76

51. Geldmacher Y, Oleszak M, Sheldrick WS. Rhodium(III) and iridium(III) complexes as anticancer agents. Inorganica Chimica Acta 2012; 393: 84-102

52. Kozakiewicz B, Dmoch-Gajzlerska E, Kaczmarczyk M, Bulska E. Na początku było vestium, teraz jest ruten. Curr Gynecol Oncol 2012; 10: $124-30$.

53. Bergamo A, Gaiddon C, Schellens JH, Beijnen JH, Sava G. Approaching tumour therapy beyond platinum drugs Status of the art and perspectives of ruthenium drug candidates. J Inorg Biochem 2012; 106: $90-9$.

54. Dickson NR, Jones SF, Burris IIIHA, et al. Aphase I dose - escalation study ofNKP-1339 in patients with advanced solid tumors refractory to treatment. J Clin Oncol 2011; 29 (suppl.): abstr. 2607.

55. Hudej R, Turel I, Kanduser M, et al. The influence of electroporation on cytotoxicity of anticancer ruthenium (III) complex KP1339 in vitro and in vivo. Anticancer Res 2010; 30: 2055-64.

56. SchmittF, Govindaswamy P,Zava O, Süss-Fink G, Juillerat-Jeanneret L Therrien B. Combined arene ruthenium porphyrins as chemo therapeutics and photosensitizers for cancer therapy. J Biol Inorg Chem 2009; 14: 101-9.

57. Davia K, King D, Hong Y, Swavey S. A porphyrin-ruthenium photo sensitizer as a potential photodynamic therapy agent. Inorg Chem Commun 2008; 11: 584-6.

58. Mangiapia G, D’Errico G, Simeone L, et al. Ruthenium-based complex nanocarriers for cancer therapy Biomaterials 2012; 33: 3770-82.

\section{Address for correspondence}

\section{Bartosz Kasprzak}

University Hospital of Lord's Transfiguration

Szamarzewskiego 82/84

60-569 Poznan, Poland

e-mail: bkasprzak@gumed.edu.pl

Submitted: 21.11 .2014

Accepted: $\quad 20.07 .2015$ 